\title{
Flux Switching Permanent Magnet Generator Design and Optimization Using Response Surface Methodology
}

\author{
Javad Soleimani $^{1}$, Abdolhossein Ejlali ${ }^{2}$, Masood Moradkhani ${ }^{3}$ \\ ${ }^{1}$ Electrical Engineering Department of Iran University of Science \& Technology (IUST), Tehran, Iran. \\ ${ }^{2}$ Department of engineering, Islamic Azad University, Ilam Branch-Center of Mehran, Ilam, Iran. \\ ${ }^{3}$ Department of Electrical Engineering, Ilam Branch, Islamic Azad University, Ilam, Iran.
}

\section{Article Info}

Received Jan 07, 2019

\section{Keyword:}

Flux Switching Permanent

Magnet Generators;

Direct Drive Wind Turbine;

Response Surface Method;

Finite Element Method;

\begin{abstract}
Flux Switching Permanent Magnet Generators (FRPMGs) have been used increasingly in direct drive variable speed wind turbines due to their merit such as their high torque density, easy flux weakening operation and robust rotor structure. Generally, the quality of output power in direct drive systems is lower than multi stage fixed speed systems, because of removing the gears, so it's important to design these kinds of generators with low ripple and lowest harmful harmonics and cogging torque. This aim is one of the most important terms in increasing the quality of output power of generator simultaneously with back-EMF improvement. The objective of this paper is introducing a simple design method and optimization of high power FRPMG applied in direct drive wind turbine system by lowest possible amplitude of cogging torque and highest possible power factor, efficiency and power density. For optimization reason an optimum method called combined response surface methodology (RSM) and design of experiment has been applied. Also in order to extract the output values of generator and sensitivity analysis for design, 2D-Finite element model, was used. This method has high accuracy and gives us a better insight of generator performance and presents back EMF, cogging torque, flux density and FFT of the FSPMG. This study can help in design approach of such machines.
\end{abstract}

\section{Corresponding Author:}

Masood Moradkhani

Department of Electrical Engineering, Ilam Branch, Islamic Azad University,

Ilam, Iran.

Email: moradkhani.m@gmail.com

\section{Introduction}

During last two decades, renewable energy sources have become crucial due to the traditional energy sources. Therefore the usage of wind energy sources has been increased. [1]

Several wind turbine concepts have been proposed. There are three major topologies of wind turbine systems: fixed-speed wind generators with multi-stage gearbox, variable speed wind generators (with single-stage or multi-stage gearbox) and direct-drive wind generators. $[2,3]$

Because of several advantages such as removal the gearbox, drive simplification, longevity, high reliability, weight reduction, maintenance cost reduction, higher aggregate efficiency, low level of vibration and noise of the drive train, simplified SCADA structure and better utilization of the available wind power, direct drive variable speed structures in wind power turbines are in attention. $[3,4]$ 
The most important part of these kinds of systems are permanent magnet type generators that have less weight and volume and less cooper and iron losses, more TPC, power factor and efficiency, less mechanical problems and more longevity than their rivals. [4-7]

Among all kinds of permanent magnet synchronous generator types, Flux Switching Permanent Magnet Generators are one of the most top options for variable speed wind turbines because of merit below [4,8-10]:

1) Easily managing temperature rise of magnets which is on the stator. 2) The PM field and the armature field are in parallel magnetic circuit structure, hence the armature field has little influence on the PMs. 3) A high per-unit winding inductance can be readily achieved which leads to a better capability to restrain short-circuit currents. 4) Easy magnet cooling and better rotor stability. 5) Lower permanent magnet used in machine structure.

In fact, a Flux-Switching Permanent Magnet (FSPM) machine is a switched reluctance machine having magnets in its stator in addition with field winding that is a concentrated windings type and a passive rotor structure, however it could be designed by an active rotor and passive stator structure. Nonetheless, compared to the active rotor topology (having magnets in the rotor), conventional FSPM machines, the placement of both PMs and windings in the stator is favourable for cooling applications where the ambient temperature of the machine may be high. By this topology, several problems regarding active rotational part such as manufacture difficulties, maintenance, rotor destruction and PM demagnetizing would be resolved. The FSPM machine may exhibit high torque density, besides the magnetic circuit of FSPM machine is short, which may result in low iron loss in the stator back-iron. [4,10]

Generally, these merit makes 3-phase topology of FSPMGs more suitable for variable-speed drive systems, in which the torque capability in the constant torque region and the flux-weakening capability in the constant power region are the two important performances. Flux density in the airgap region could reach to 2.5 Tesla, besides, the PM orientation and windings are magnetically parallel and it can remove the armature reaction effect in working point and increase the electric loading. [4,10-14]

Because of removing the gears, it's important to design these kinds of generators with low ripple and lowest harmful harmonics and cogging torque that is one of the most important terms in increasing the quality of output power of generator [11-16]. Cogging torque in these machines is quite dependent on the geometry of teeth in both sides (rotor and stator) and volume of PMs in each stator tooth. In order to design a FSPM machine by lower rate of leakage flux, higher efficiency and power factor but the lower amplitude of cogging torque, isolating gaps in stator teeth between different phase windings was used. [17,18]

This paper implemented a simple design and optimization method of high power FSPMG applied in direct drive wind turbine system by lowest possible amplitude of cogging torque and highest possible power factor, efficiency and power density. For this purpose, a 2D-finite element model and an optimum method called combined response surface methodology (RSM) was applied. This method can achieve excellent performance and low costs by optimizing multiple design variables of FSPMG [16], and has high level of accuracy and gives a better insight of generator performance.

\section{Structure and Configuration}

FSPM machines have unequal stator and rotor poles and are capable to design by odd or even number poles in both sides. Fig. 1 shows the cross-sections of a prototype 3-phase, 12/10-pole FSPM machine by passive stator structure. $[4,10]$ It can be seen that the PMs in these kinds of machines will placed between two stator teeth and magnetize circumferentially and each PM has magnetic orientation in apposite of its nearest neighbours also the rotor of the machine is similar to that of a switched reluctance machine. Obviously, for this prototype each phase consists of 2 windings in series and each winding has 2 coils $[4,15]$. In this paper, an active stator type FSPMG by isolating gaps in stator teeth between different phase windings will design based on turbine speed and torque so a direct drive wind generator system operating again at Ten $=200 \mathrm{k} . \mathrm{Nm}$ and $\mathrm{n}=30 \mathrm{rpm}, \mathrm{fn} \approx 100 \mathrm{~Hz}$ will be designed and simulated. [4,11]

\section{Design Method}

By using the PM flux concentration, we can adopted a larger force density ftn to offset the effect of the inductance increase due to the fringing effect: $\mathrm{ftn}=6 \mathrm{~N} / \mathrm{cm} 2$. Table. 1 shows the geometrical parameters and their values and the designing equations. $[4,11,15,19,20]$. 
Fig.2 shows the machine geometry represented with one pole, some of stator and rotor geometric details were illustrated in this figure. The ideal PM flux density in the airgap BgPMax is could be found as $[4,11,15]$ :

$$
B_{g P \text { Maxi }}=\frac{B_{r}}{\frac{W_{t s}}{h_{P M}}+\frac{\mu_{r e c}}{\mu_{0}} \cdot \frac{2 \cdot g}{\tau_{P M}}}
$$

This expression is derived from equations below $[4,11,15]$ :

$$
\begin{aligned}
& B_{m} \cdot h_{P M}=B_{g} \cdot W_{t s} \\
& H_{m} \cdot l_{P M}+\frac{B_{q}}{\mu_{0}} \cdot 2 \cdot g=0 \\
& B_{m}=B_{r}+\mu_{r e c} \cdot H_{m}
\end{aligned}
$$

Fig. 3 shows the magnetic characteristics diagram of soft magnetic material used in stator and rotor core: Initial Relative Permeability is equal to 6000, Saturation Magnetization is 1.6 Tesla and knee adjusting coefficient is 0.3 [15].

Fig. 4 shows the magnetic characteristics diagram of PM used in rotor structure (Nd-Fe-B). For this reason a linear approximation has been used. Remanent Flux Density $\left(\mathrm{B}_{\mathrm{r}}\right)$ of used PM is 1.3 Tesla and the Relative Permeability $\left(\mu_{\mathrm{rec}}\right)$ is $1.05 \mu_{0}[15]$.

The fringing effect will reduce the ideal PM airgap flux density to a smaller value $[4,11,15]$ :

$$
B_{g P M a x}=\frac{B_{g P M a x i}}{\left(1+k_{\text {fringe }}\right) \cdot\left(1+k_{s}\right)}
$$

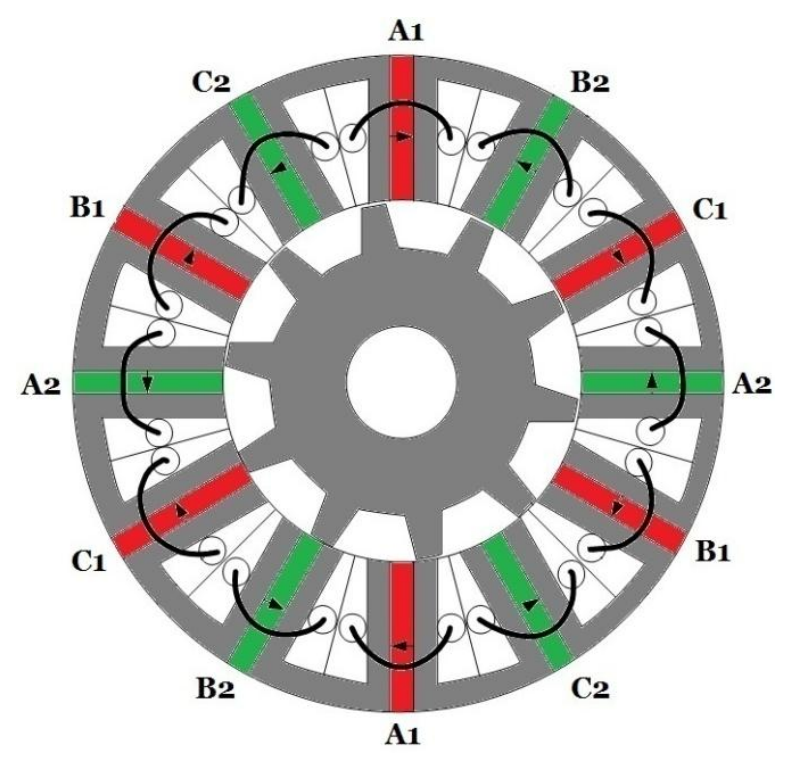

Figure 1. Topology of 12/10, 3-phase FSPM machine

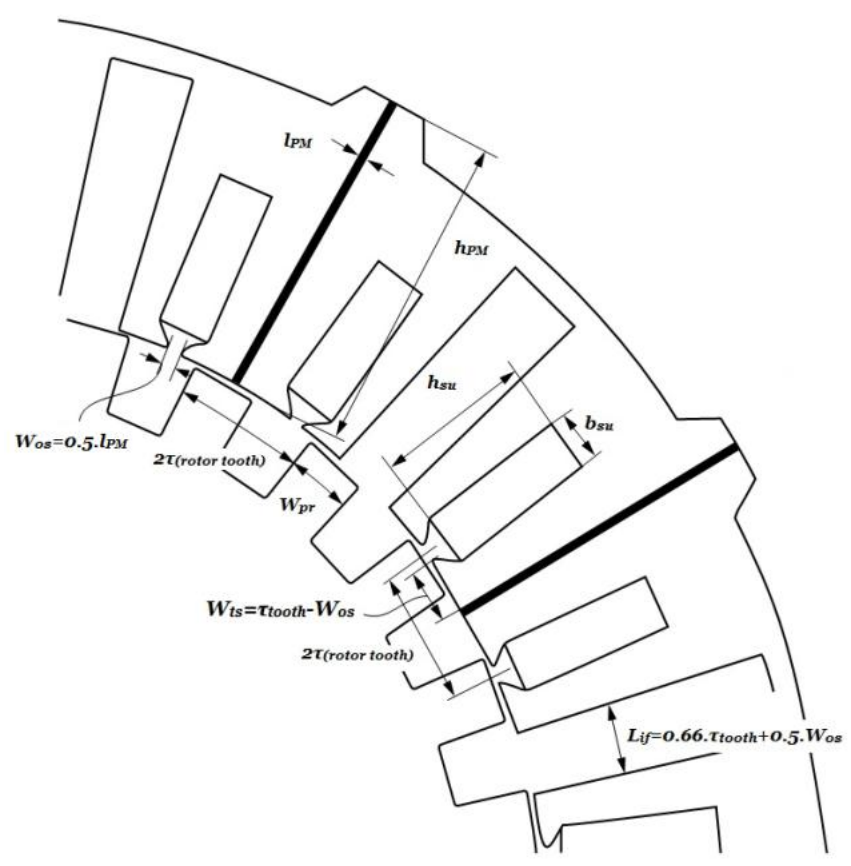

Figure 2. Flux Switching PM generator geometry 
Table. 1: Geometrical parameters and their equations

\begin{tabular}{|c|c|c|}
\hline Parameter & Equation & Value \\
\hline Nominal power of the generator & $P_{n}=T . \Omega=\frac{200 \times \pi \times n_{n}}{60}$ & $628.3185 \mathrm{w}$ \\
\hline length to diameter $(\mathrm{L} / \mathrm{D})$ ratio & $\lambda=1$ stack $/$ Dis & 0.133 \\
\hline Inner stator diameter & $D_{i s}=\sqrt[3]{\frac{2 \cdot T_{e n}}{\pi \cdot f_{t n} \cdot \lambda}}=\sqrt[3]{\frac{2 \times 200 \times 10^{3}}{\pi \times 6 \times 10^{4} \times 0.133}}$ & $2.515 \mathrm{~m}$ \\
\hline Stack length & $l_{\text {stack }}=\lambda \cdot D_{i s}=0.133 \times 2.515$ & $0.3345 \mathrm{~m}$ \\
\hline Inner radius of the stator & ris $=$ Dis $/ 2$ & $1257.5 \mathrm{~mm}$ \\
\hline $\begin{array}{c}\text { Number of rotor salient poles (first } \\
\text { estimation) }\end{array}$ & $N_{r} \approx \frac{f_{n}}{n}$ & $N_{r} \approx \cdot 200$ \\
\hline $\begin{array}{l}\text { Number of rotor salient poles correction (K } \\
\text { should be a natural number) }\end{array}$ & $2 \cdot N_{r} \cdot \tau=6 \times k \times\left(4 \cdot \tau+\frac{2 . \tau}{3}\right)=28 \cdot k \cdot \tau$ & $\begin{array}{c}\mathrm{Nr}=196 \\
\mathrm{~K}=14\end{array}$ \\
\hline Number of stator poles (Number of PMs) & $\mathrm{Ns}=6 . \mathrm{K}$ & $\mathrm{Ns}=84$ \\
\hline Frequency correction & $f_{n} \approx N_{r} \cdot n$ & $98 \mathrm{~Hz}$ \\
\hline $\begin{array}{l}\text { Arc length of an stator pole considering an } \\
\text { isolating gap, a PM thickness and } 2 \text { stator } \\
\text { solts }\end{array}$ & $\theta_{i s}=\frac{180}{N_{s}}=\frac{l_{i s}}{r_{i s}} \cdot \frac{180}{\pi}$ & $47 \mathrm{~mm}$ \\
\hline $\begin{array}{c}\text { Outer rotor radius (by considering } \\
\text { airgaplength, } \mathrm{g}=2 \mathrm{~mm} \text { ) }\end{array}$ & ror $=$ ris $-\mathrm{g}$ & $1255.5 \mathrm{~mm}$ \\
\hline Arc length of a rotor pole & $\theta_{o r}=\frac{180}{N_{r}}=\frac{l_{o r}}{r_{o r}} \cdot \frac{180}{\pi}$ & $20.1 \mathrm{~mm}$ \\
\hline
\end{tabular}
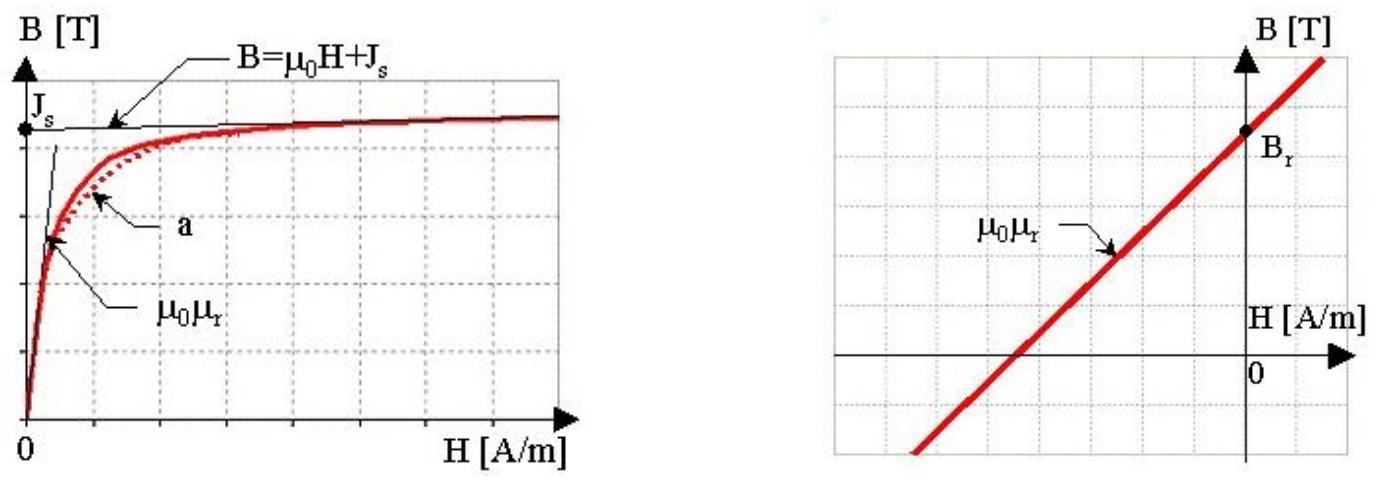

Figure 3. Magnetic characteristics diagram of soft Figure 4. Magnetic characteristics diagram of PM magnetic material used in stator and rotor core. used in stator structure.

With $\mathrm{k}_{\text {fringe }}=1.5, \mathrm{ks}=0.2$, we set the actual airgap flux density $\mathrm{B}_{\mathrm{gPMax}}$ at a reasonable value, say $\mathrm{B}_{\mathrm{gPMax}}=0.7$ Tesla, so $\mathrm{B}_{\text {gPMaxi }}$ would be 2.1 Tesla. From the equation 1, the PM height $\mathrm{h}_{\mathrm{PM}}$ would be $120 \mathrm{~mm}$, therefore the outer stator diameter would be $2635 \mathrm{~mm}$. The PM maximum flux per coil turn could be 2.81 mili weber and obtained from equation below:

$$
\phi_{P M a x c}=B_{g P \operatorname{Max}} \cdot W_{t s} \cdot l_{\text {stack }}
$$

The maximum flux linkage is $[4,11,15]$ :

$$
\Psi_{\text {PMphase }}=2 \cdot k \cdot \phi_{P \text { Maxc }} \cdot n_{c}=2.14 \times 2.81 \times 10^{-3} \times n_{c}=0.07867 \times n_{c}
$$


The Emf per phase (peak value) Em is:

$$
E_{m}=2 \cdot \pi \cdot f_{1} \cdot \Psi_{\text {PMphase }}=2 \times \pi \times 93 \times 0.07867 \times n_{c}=45.949 \times n_{c}
$$

The ampere turns per slot would be 6458.9 and may be calculated as $[4,11,15,19,20]$ :

$$
n_{c} \cdot I_{n}=\frac{2 \cdot n_{c}}{3 \sqrt{2}} \cdot T_{e n} \cdot \frac{2 \cdot \pi \cdot n}{E_{m}}
$$

The slot width is about equal to the pole pitch (Fig. 2), we consider it $22 \mathrm{~mm}$ as below:

$$
\mathrm{bsu} \approx(1 \text { to } 1.2) \times \tau \mathrm{PM}
$$

Also, the stator tooth average width is around half the pole pitch $\tau \mathrm{PM}$. The total slot height could be obtained from Fig. 2 and is $90 \mathrm{~mm}$. The current density required to host the coil jcon is $6.524 \mathrm{~A} / \mathrm{mm} 2$ as follows $[4,11,15,19,20]$ :

$$
j_{c o n}=\frac{n_{c} \cdot I_{n}}{h_{s u} \cdot W_{t s} \cdot k_{\text {fill }}}
$$

By having stator slot cross section, current density and obtained ampere turn, it can use 11 turns of wires each turn $90 \mathrm{~mm} 2$, the nominal voltage would be 505.44 volt. Length of each coil could be obtained as $[4,11]$ :

$$
l_{\text {coil }}=2 l_{\text {stzck }}+4 \tau_{P M}+\pi W_{t s}
$$

The stator coil resistance is:

Then, for the entire phase:

$$
R_{s c}=\rho_{c o} \cdot \frac{l_{c o i l}}{\frac{n_{c} \cdot I_{n}}{j_{c o n}}} \cdot n_{c}^{2}
$$

$$
R_{s}=2 k R_{s c}
$$

Fig. 5, shows the concentrated winding diagram of the presented 3-phase, 12/10-pole FSPM prototype in Fig. $1[4,10,15,21,22]$. As it can be illustrated, namesake winding coils' located in 180 mechanical degree from each other and each phase has 2 parallel windings and each winding has 2 coils in series.

So, by using this method of winding, for the designed prototype (3-phase 84/196 FSPMG), each phase has 14 parallel windings and each winding has 2 coils in series, also namesake winding coils' located in 180 mechanical degree from each other as it be noted [4, 10,15,21,22]. This simulation is based on circuit coupled model using the phase voltage as input quantity, Fig. 6 shows the circuit coupled model that is used in this study, Fig. 6-a shows one half of the designed FSPMG, green colour shows windings for phase-a, black colour for phase-b and red colour for phase-c, determinate in stator slots.

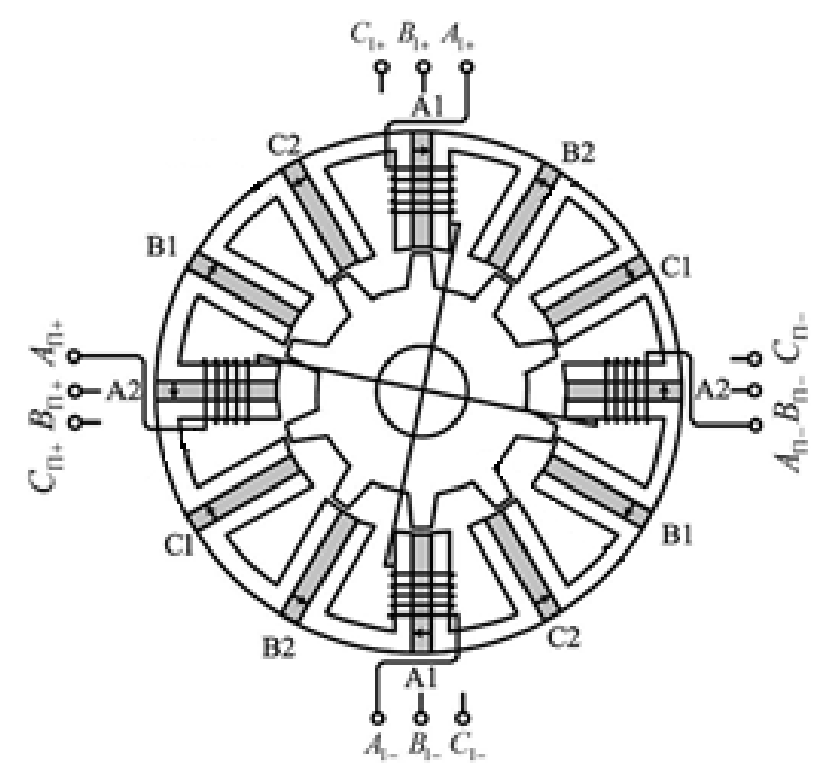

Figure 5. Concentrated winding diagram for a 12/10 FSPM 


\section{FEM Model}

Finite element method (FEM) is the most widely used numerical analysis method in the computer simulations. The FEM does not require a physical prototype production and it can be used to analyze any parts/components of the whole system under certain operating conditions. Also, it permits improvements in the reliability of product by changing the design according to the results of analysis. [23,24]

As it has been mentioned, a 2D-finite element model is implemented in order to simulate the proposed FSPM generator. This 2D model has simple, high level of accuracy and gives a quick and better insight of machine performance.

In order to have high level of accuracy the mesh diagram is designed manually, in this simulation node congestion is higher around the air gap and stator and rotor teeth. The total number of nodes is about 286680 for the half part of machine, that lead to high level of accuracy, meanwhile, for boundary conditions, the homogenous dirichlet condition is adopted on the infinite box that encompasses the generator, according to this assumption on infinite box flux distribution is zero. It must be noted that one half of PMSG is analyzed because of the magnetic periodicity of the machine, as seen in Fig. 7, nodes congestion becomes higher near the air gap in order to accurate simulation. Based on FEM model the simulation of the generator is done and output characteristics are extracted.

\section{Optimization Methodology}

In order to choose an accurate volume of permanent magnet regarding to magnetic circuit that PM material is in, airgap length $(\mathrm{lg})$ and the PM thickness $(\mathrm{lm})$ as it has been mentioned, RSM method and design of experiment was applied. RSM is a set of statistical and mathematical techniques. In RSM, a polynomial model is constructed to represent the relationship between the performance and multiple design variables. The ultimate goal of RSM is to find the best fitted response of the physical system through real experiment or computer simulation [25]. Research and application of RSM as an optimization method have been carried out in many fields [26-28]. As a summary, RSM combined with design of experiment is regarded as an ideal method to perform the optimum design for TFM generator [16].

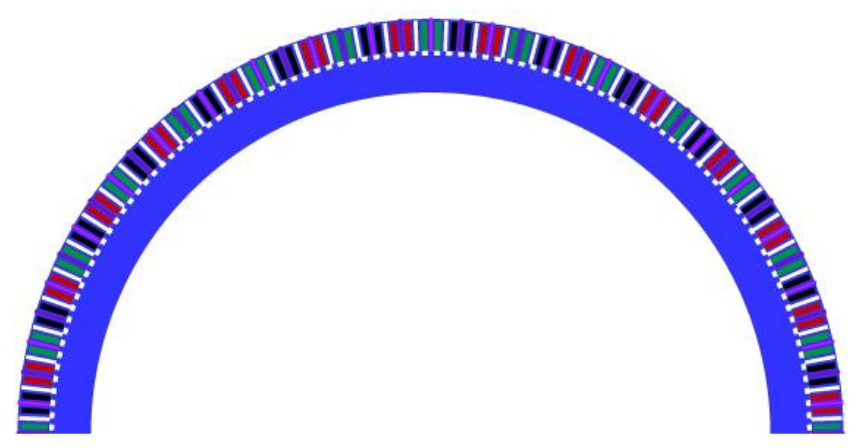

(a)

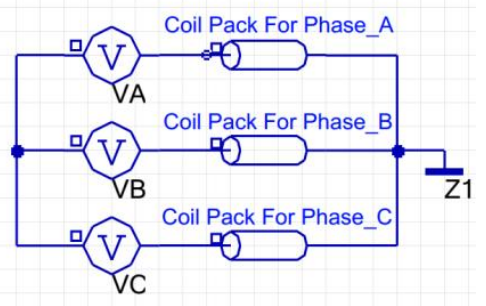

(b)

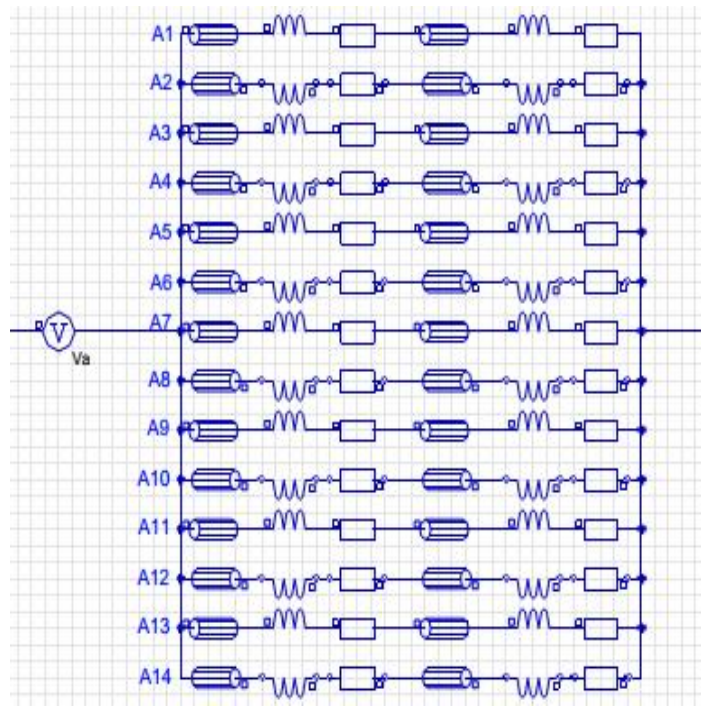

(c)

Figure 6. Concentrated winding diagram for a half part of the 84/196 FSPMG (a) determination of the slots for each phase. (b) Electrical circuit for winding connection. (c) Electrical circuit for coils connection in a sample phase (14 parallel windings in phase-a containing 2 coils in each winding) 

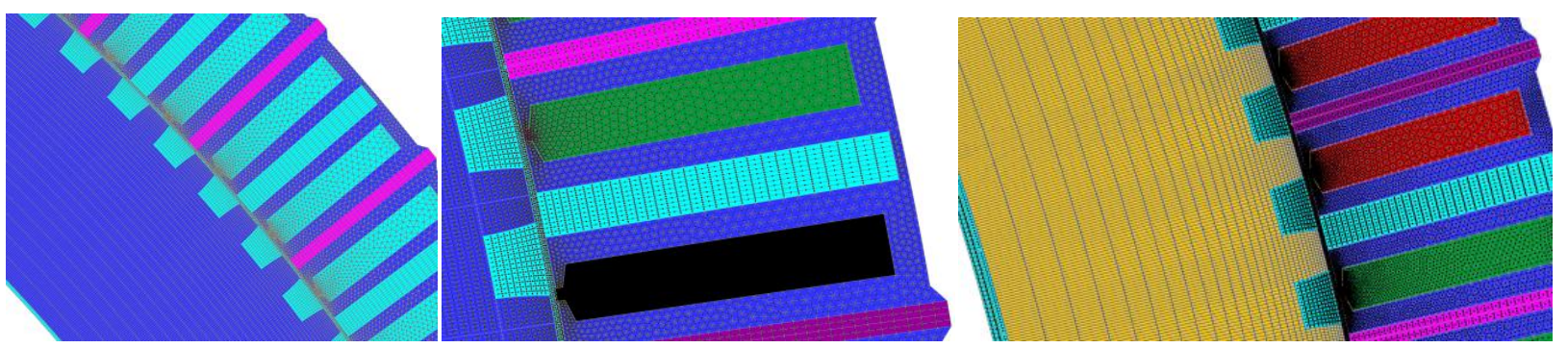

Figure 7. Mesh diagram of simulated machine

Design of experiment can be regarded as a carefully arranged experiment procedure. The purpose of design of experiment is two-fold. The first is to make the experiment procedure reasonable and can be conducted orderly; and the second is to get adequate and reliable information by minimal number of experiments [16, 2531].

Design of Experiments (DOE) is statistical tool deployed in various types of system, process and product design, development and optimization. It is multipurpose tool that can be used in various situations such as design for comparisons, variable screening, transfer function identification, optimization and robust design. [30,31] Design of Experiments (DOE) mathematical methodology used for planning and conducting experiments as well as analyzing and interpreting data obtained from the experiments. It is a branch of applied statistics that is used for conducting scientific studies of a system, process or product in which input variables (Xs) were manipulated to investigate its effects on measured response variable (Y). [31] Factorial experiments can be design with one, two, three and more factors. Experiments with only one factor are often called simple comparative experiments. [31]

For this methodology, the crucial parameters are: airgap length $(\lg ) \mathrm{dv} 1$, PM thickness $(\operatorname{lm}) \mathrm{dv} 2$, overlap between PM and rotor length in radial direction (hR) and outer rotor radios (Dr) dv3, because of their effect on cogging torque and output back EMF of the generator. The overlap is defined as zero when $\mathrm{hR}=0$ and it is defined as $100 \%$ when $\mathrm{hR}=$ Dr. Therefore, $\mathrm{dv} 1, \mathrm{dv} 2$, and $\mathrm{dv} 3$ are selected as the design variables to optimize the performance of FSPM generator.

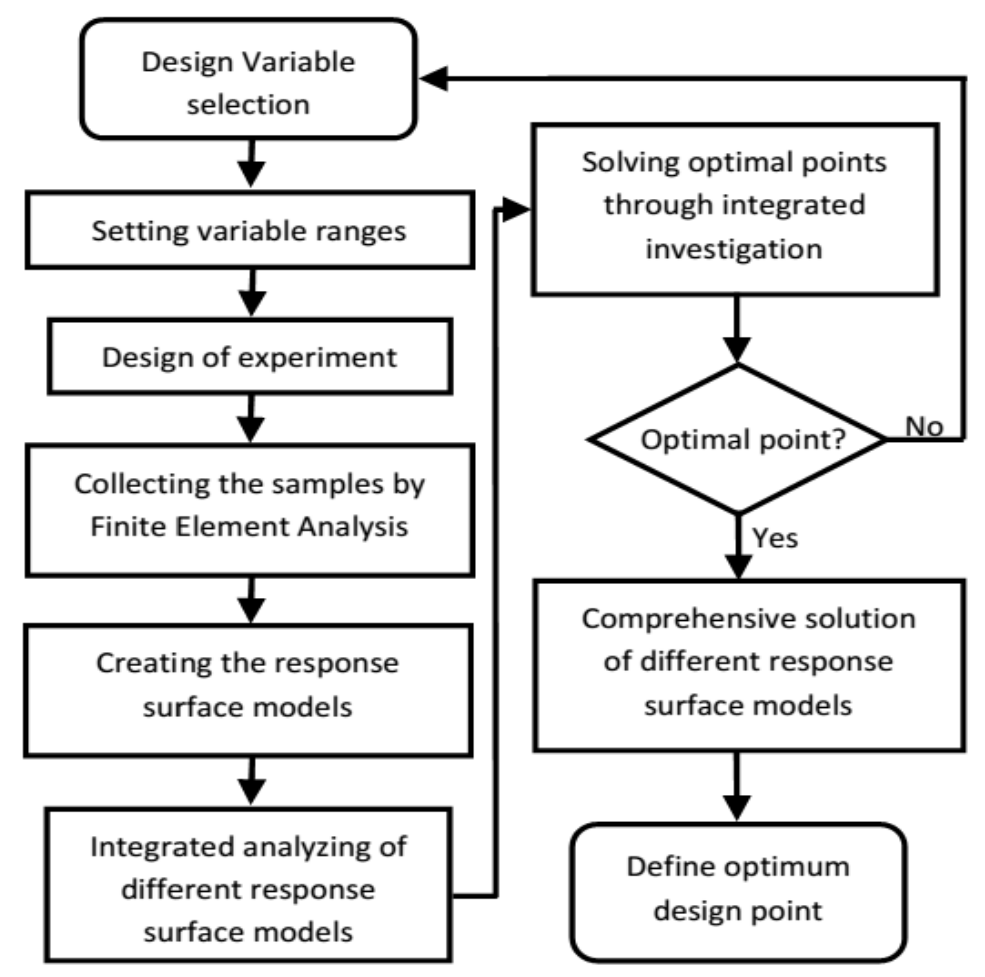

Figure 8. Optimum design process of proposed FSPM generator using RSM 
Fig. 8 shows the optimum design process applied in this study using RSM. Table 2 shows the design variables and levels. The design variables in zero level are the values of the initially design. The design variables in $-\alpha$ level and $+\alpha$ level, which are determined by possible values of the three design variables, decide the minimum and maximum respectively [16, 25-29]. Design of experiment procedure and Response surface methodology has been implemented based on [16], with the three design variables dv1, dv2 and dv3, CCD is required to perform 15 experiments, The 2D finite element model is analyzed for each experiment and the cogging torque and the back EMF are calculated. The main achievements of this method are:

- Finding the accurate dimensions (PM thickness (1PM), slot outset (Wos), Stator teeth thickness, Outer rotor diameter (Dr), airgap length (lg) and $\mathrm{hR}$ ).

- Reaching to cogging torque less than $5 \%$ of rated torque and suitable waveform for cogging torque and back EMF equal to amplitude of input voltage per phase.

Table 2. Design variables and levels implemented in RSM

\begin{tabular}{|c|c|c|c|c|c|}
\hline \multirow{2}{*}{$\begin{array}{c}\text { Design } \\
\text { variables }\end{array}$} & \multicolumn{5}{|c|}{ levels } \\
\cline { 2 - 6 } & $-\alpha$ & -1 & 0 & +1 & $+\alpha$ \\
\hline $\mathrm{dv} 1(\mathrm{~mm})$ & 0.5 & 1 & 3 & 5 & 8 \\
\hline $\mathrm{dv} 2(\mathrm{~mm})$ & 4 & 6 & 8 & 10.5 & 13 \\
\hline $\mathrm{dv} 3(\%)$ & 1 & 2 & 3 & 5 & 10 \\
\hline
\end{tabular}

Table 3. RSM method results

\begin{tabular}{|c|c|c|}
\hline Parameter & $\begin{array}{c}\text { Primary } \\
\text { value }\end{array}$ & $\begin{array}{c}\text { Optimal } \\
\text { value }\end{array}$ \\
\hline PM thickness (lPM) & $8(\mathrm{~mm})$ & $7(\mathrm{~mm})$ \\
\hline Slot outset (Wos) & $8(\mathrm{~mm})$ & $4(\mathrm{~mm})$ \\
\hline Outer rotor diameter $(\mathrm{Dr})$ & $2511(\mathrm{~mm})$ & $2511(\mathrm{~mm})$ \\
\hline Cogging torque & $810(\mathrm{~N} . \mathrm{m})$ & $694(\mathrm{~N} . \mathrm{m})$ \\
\hline Back EMF amplitude & $604(\mathrm{v})$ & $640(\mathrm{v})$ \\
\hline
\end{tabular}

\section{Simulation Results and Discussion}

Based on the above methodology, finite element simulations for the 3-Phase, 84/196 FSPM generator with active stator with concentrated winding has been done in each step. It must be noted that one half cross section is analyzed in 2D FEM because of the magnetic periodicity of the machine. Table. 3 shows the varieties of the FSPM generator dimensions after using the optimization method. As it can be observed from the simulation results, this procedure is so effective to find the optimal dimensions of PM, airgap length and the inner diameter of the stator.

Fig. 9-a,b,c and d show the isovalues diagram and paths of flux density. Fig. 9-d also shows the distribution of flux at rated power in magneto static mode. The red lines show the flux in clockwise direction and the counter clockwise direction. This figure shows the accuracy of assignment of PMs and the correctness of the simulation.

As it can be seen from this figure, flux density at the airgap space and the iron cores in the rotor teeth and stator teeth are the highest amount. Hot spots can be seen in the stator yokes near the PMs, the other parts of rotor and stator cores don't have hot spot and it shows the iron loss in the machine is low.

Fig. 10 shows the flux density variation along the airgap during the rotating the rotor for 0.0357 second equal to 12.85 degree in magneto static mode, this can demonstrate the accuracy of simulation. 


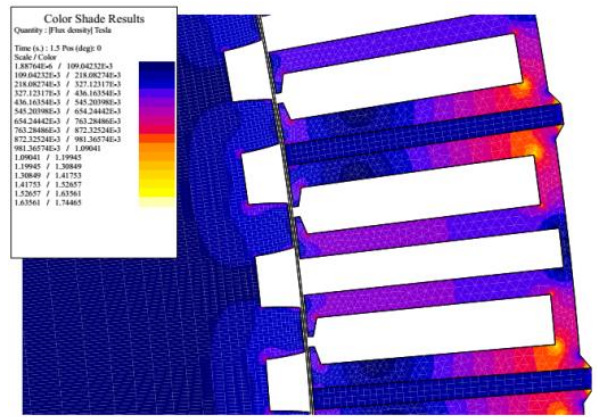

(a)

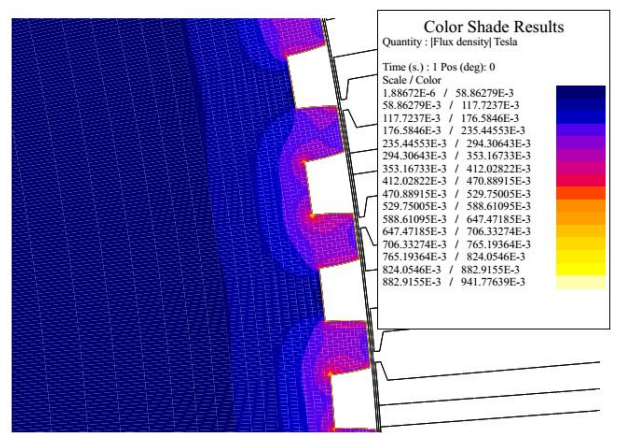

(c)

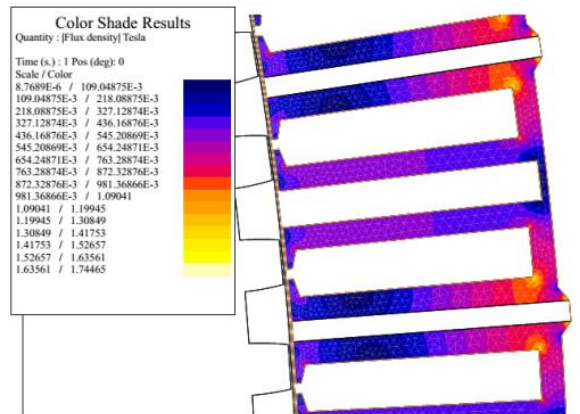

(b)

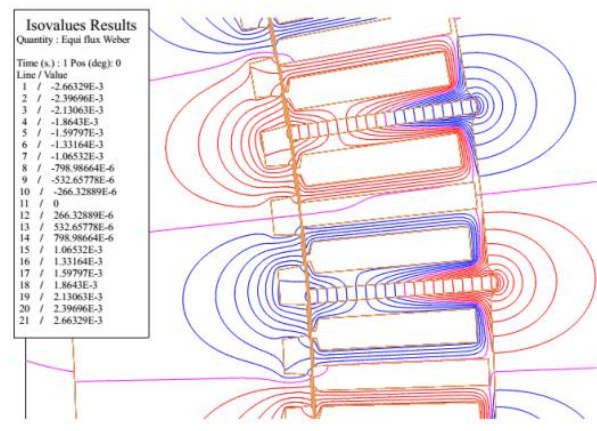

(d)

Figure 9. Flux lines and flux density in magneto static mode for FSPM generator (a) Distribution of flux density in stator and rotor in the preliminary steps (b) Distribution of flux density in stator core (c) Distribution of flux density in rotor core (d) Flux lines

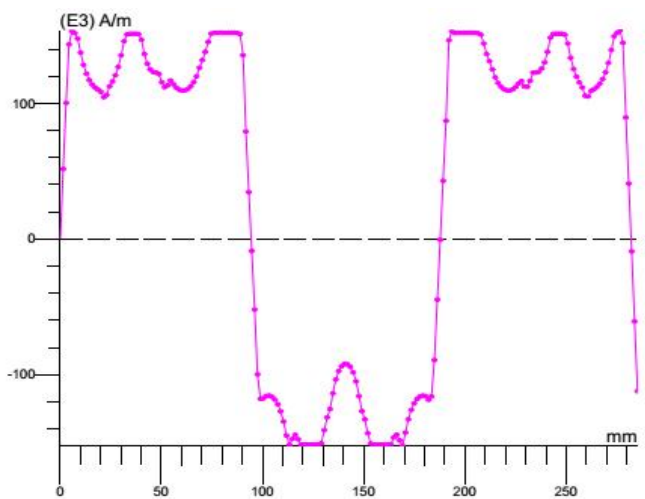

Figure 10. Flux density variation along the airgap during the rotating the rotor

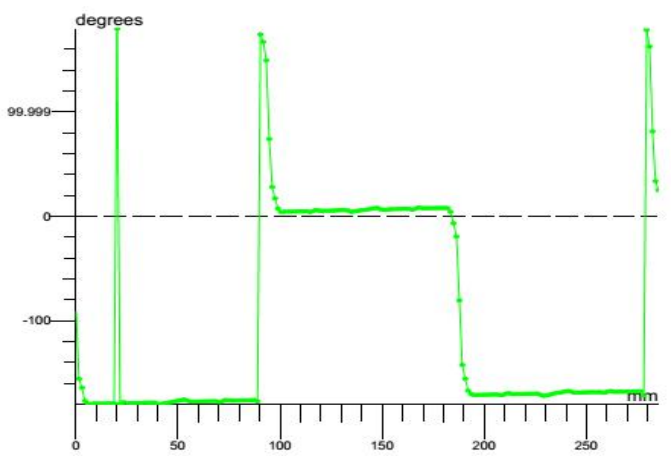

Figure 12. Magnetic field variation along the airgap for 360 mechanical degree

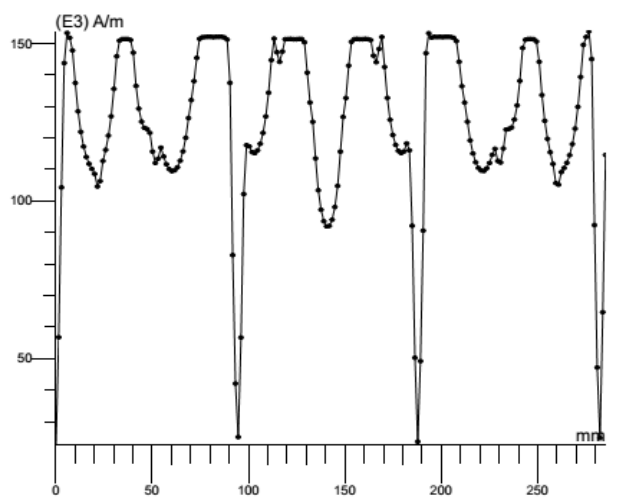

Figure 11. Magnetic field variation along the airgap during the rotating the rotor

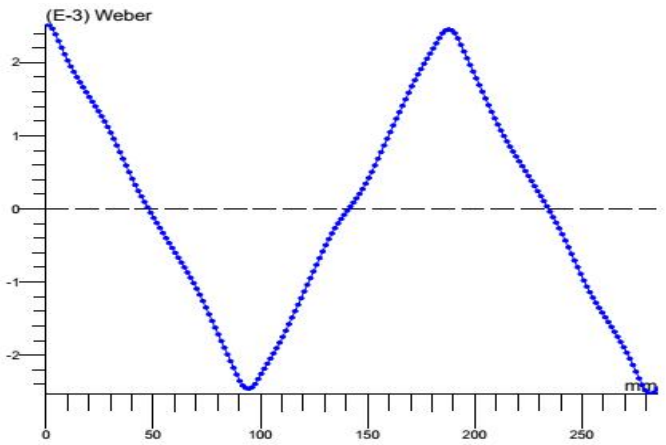

Figure 13. Permanent magnet linkage flux variation along the airgap 
Magnetic field created along the airgap space for 0.0357 second equal to 12.85 degree that is equal to 3 stator and 7 rotor poles shown in Fig. 11. For 360 degree of mechanical rotation (-180 to 180), magnetic field along the airgap shown in Fig. 12. Also, Fig. 13 shows the magnetic linkage flux variation of PM along the airgap 3 stator and 7 rotor poles. Noted to the amplitude of magnetic flux and it's equal to $2.8 \mathrm{mWeb}$, equivalent to the extracted value from the computed one.

Fig. 14 shows the cogging torque diagram by optimal values of geometry obtained by RSM. As it can be observed from this figures, cogging torque has reached to about 694 Newton. This small value is because of the geometry of rotor teeth and passive rotor structure and circumferentially magnetized PMs in the stator structure. Fig. 15 shows the cogging torque based on mechanical position of the rotor and by higher amounts of sampling than previous figure for 3 stator poles.Fig. 16 represent the magnetic force on the rotor structure along the airgap space for 0.0357 second equal to 12.85 degree arc that is equal to 3 stator and 7 rotor poles. Fig 17 shows the extracted back EMF for one phase of the FSPMG and it's obvious that amplitude of back EMF per phase is equal to the amplitude of input voltage per phase (640 Volt).

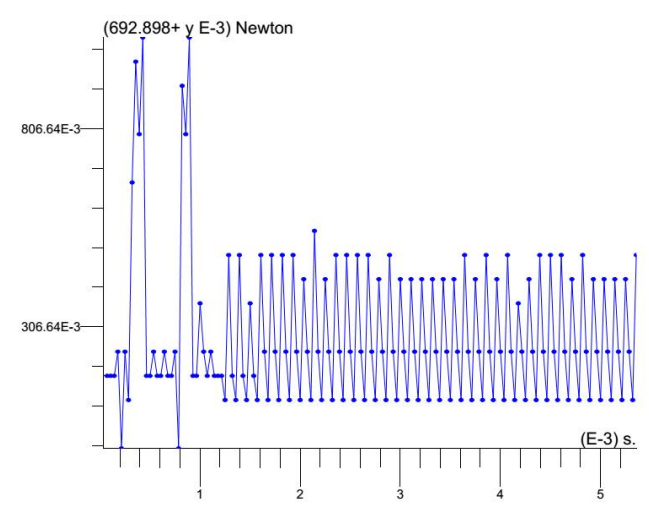

Figure 14. Cogging torque diagram for FSPM generator per second

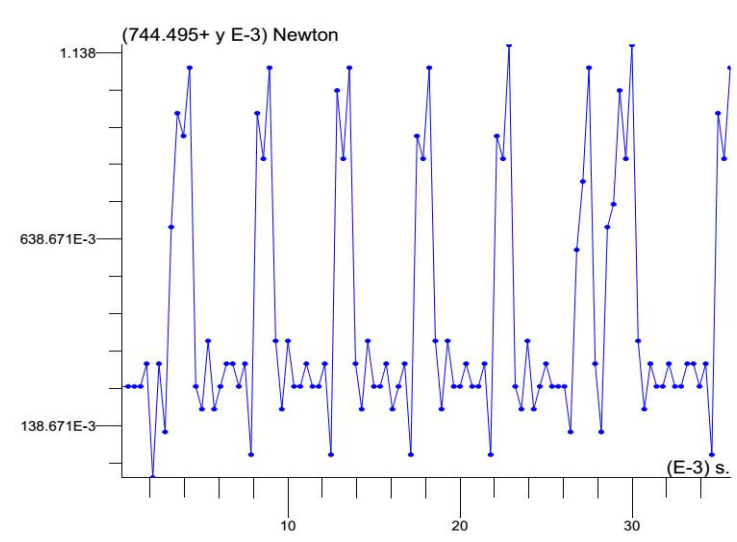

Figure 16. Magnetic force on the rotor structure along the airgap

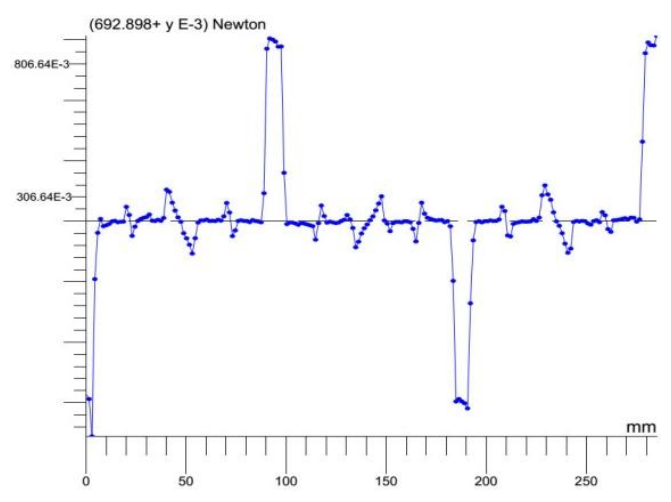

Figure 15. Cogging torque diagram for FSPM generator per mechanical position

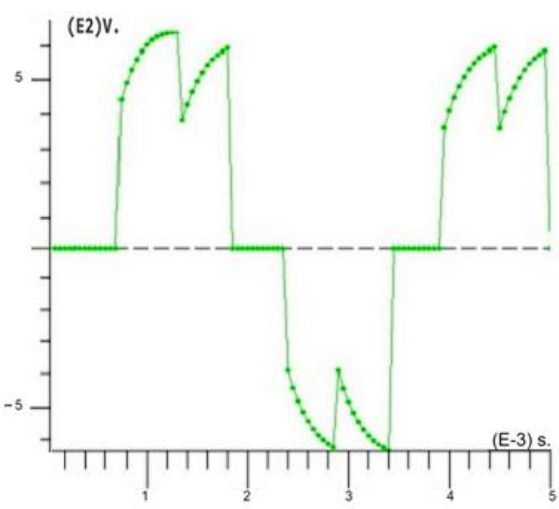

Figure 17. Extracted back EMF for one phase of simulated FSPM generator

The output current per phase of simulated FSPM generator by considering the extracted back EMF has been shown is Fig. 18. It's shown that the extracted value from the FEM is close to the value extracted in design method. Also, the harmonic behaviour of the output current is shown in Fig. 19. The results shows the authenticity of the simulated and accuracy of the proposed method for FSPM generator design, this fig shows the 3 th and 5 th harmonics respectively are equal to $23 \%$ and $8 \%$ of nominal current.

Fig. 19 shows the electromagnetic torque of the simulated and optimized machine. This figure shows the 200 Kilo Newton of electromagnetic torque as it was our goal by having about than $4 \%$ of torque ripple. 


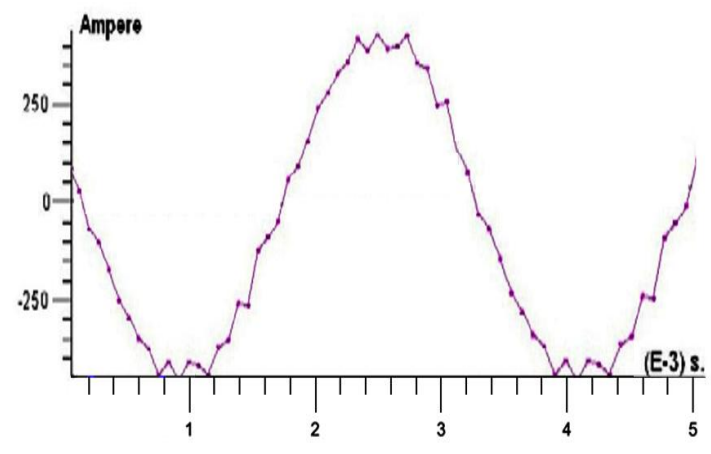

Figure 18. The output current per phase of simulated FSPM generator

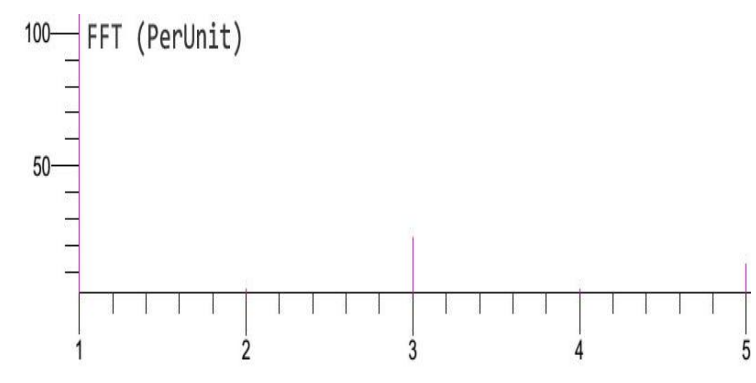

Figure 19. Harmonic Spectrum of generator's output current

\section{Conclusion}

In this paper a simple design method and optimization was introduced for a high power FSPMG applied in direct drive wind turbine system by lowest possible amplitude of cogging torque and highest possible power factor, efficiency and power density. For this reason an optimum method called combined response surface methodology (RSM) and design of experiment and in order to extract the output values of generator and sensitivity analysis for design and optimization, a 2D-Finite element model was used. This method has high accuracy and gives us a better insight of generator performance and presents back EMF, cogging torque, flux density and FFT of FSPMG. This study can help designers in design approach of such machines.

\section{References}

[1] M. C. Toklu, O. Uygun, "Location Selection for Wind Plant using AHP and Axiomatic Design in Fuzzy Environment", Periodicals of Engineering and Natural Sciences, vol. 6, no. 2, pp. 120-128, 2018.

[2] Polinder, H.; van der Pijl, F.F.A.; de Vilder, G.-J.; Tavner, P.J., "Comparison of direct-drive and geared generator concepts for wind turbines," Energy Conversion, IEEE Transactions on , vol.21, no.3, pp.725,733, Sept. 2006

[3] F. Valentin, T. Nica, K. Leban, E. Ritchie, "Direct Drive TFPM Wind Generator Analytical Design Optimized for inimum Active Mass Usage", The 8th International Symposium on Advanced Topics in Electrical Engineering, May 23-25, 2013, Bucharest, Romania.

[4] J. Soleimani, A. Ejlali, "Non-Conventional Electric Machines (Theory, Design \& Analysis)-Chapter 3", ISSN: 978-600-5714-18-0, NahrDanesh Publisher, Feb 2015, Tehran, Iran.

[5] J. Soleimani, A. Vahedi and A. Ejlali, "Study on Inner PMSM for HEV Traction Drive Application Considering Permanent Magnet Type and Temperature", Turkish Journal of Electrical Engineering and Computer Sciences, Volume 22, Issue 6, (2014).

[6] J. Soleimani, A. Vahedi and S. M. Mirimani, "Inner Permanent Magnet Synchronous Machine Optimization for HEV Traction Drive Application in Order to Achieve Maximum Torque per Ampere", Iranian Journal of Electrical and Electronic Engineering, Vol.7 No.4, Dec 2011.

[7] R. Kerid, H. Bourouina, R. Yahiaoui, "Parameter identification of PMSM using EKF with temperature variation tracking in automotive applications", Periodicals of Engineering and Natural Sciences, vol. 6, no. 2, pp. 109-119, 2018.

[8] Xiaohong Xue; Wenxiang Zhao; Jihong Zhu; Guohai Liu; Xiaoyong Zhu; Ming Cheng, "Design of FivePhase Modular Flux-Switching Permanent-Magnet Machines for High Reliability Applications," Magnetics, IEEE Transactions on, vol.49, no.7, pp.3941,3944, July 2013

[9] Yu Wang; Zhiquan Deng, "A Multi-Tooth Fault-Tolerant Flux-Switching Permanent-Magnet Machine With Twisted-Rotor," Magnetics, IEEE Transactions on, vol.48, no.10, pp.2674,2684, Oct. 2012 
[10] W. Hua, M. Cheng, Z. Q. Zhu, D. Howe, "Design of Flux-Switching Permanent Magnet Machine Considering the Limitation of Inverter and Flux-Weakening Capability", Industry Applications Conference, USA, 2006.

[11] I. Boldea, "Variable Speed Generators-Chapter 11", ISBN 0- 8493-5715-2, CRS Press Taylor \& Francis, USA, 2007.

[12] Pellegrino, G.; Gerada, C., "Modeling of Flux Reversal Machines for direct drive applications," Power Electronics and Applications (EPE 2011), Proceedings of the 2011-14th European Conference on , vol., no., pp.1,10, Aug. 30 2011-Sept. 12011

[13] Yubin Wang; Jianxin Sun; Zhixiang Zou; Zheng Wang; Chau, K.T., "Design and Analysis of a HTS Flux-Switching Machine for Wind Energy Conversion," Applied Superconductivity, IEEE Transactions on , vol.23, no.3, pp.5000904,5000904, June 2013

[14] Pellegrino, G.; Gerada, C., "Modeling of Flux Reversal Machines for direct drive applications," Power Electronics and Applications (EPE 2011), Proceedings of the 2011-14th European Conference on , vol., no., pp.1,10, Aug. 30 2011-Sept. 12011

[15] J. Soleimani, A. Ejlali, "Flux Switching Generator Applied in Wind Turbine Systems", Technical Report, Azad University of Ilam, Iran, Jan 2017.

[16] J. Xie, D. Kang, B. C. Woo, J. Y. Lee, Z. H. Sha, S. D. Zhao, "Optimum Design of Transverse Flux Machine for High Contribution of Permanent Magnet to Torque Using Response Surface Methodology, Journal of Electrical Engineering \& Technology Vol. 7, No. 5, pp. 745 752, 2012.

[17] A. Ejlali, Javad Soleimani \& A. Vahedi, "Review in Transverse Flux Permanent Magnet Generator Design and Optimization", Iranian Journal of Electrical and Electronic Engineering, Vol.12 No.4, Dec 2016.

[18] Li Hao; Mingyao Lin; Da Xu; Wei Zhang, "Cogging Torque Reduction of Axial Field Flux-Switching Permanent Magnet Machine by Adding Magnetic Bridge in Stator Tooth," Applied Superconductivity, IEEE Transactions on, vol.24, no.3, pp.1,5, June 2014

[19] Somesan, L.; Padurariu, E.; Viorel, 1.-A.; Szabo, L., "Design of a permanent magnet flux-switching machine," ELEKTRO, 2012, vol., no., pp.256,259, 21-22 May 2012.

[20] Liviu Emilian SOMESAN, Ioan Adrian VIOREL, " Permanent Magnet Flux-Switching Machine, Optimal Design and Performance Analysis ", Advances in Electrical and Electronic Engineering 11(2):46-53 - July 2013.

[21] Chang-Chou Hwang; Chia-Ming Chang; San-Shan Hung; Cheng-Tsung Liu, "Design of High Performance Flux Switching PM Machines with Concentrated Windings," Magnetics, IEEE Transactions on , vol.50, no.1, pp.1,4, Jan. 2014.

[22] More, D.S.; Fernandes, B.G., "Power density improvement of three phase flux reversal machine with distributed winding," Electric Power Applications, IET , vol.4, no.2, pp.109,120, February 2010.

[23] S. Komurcu, "Numerical Modelling of the In-Plane Loaded Homogenized Masonry Walls", Periodicals of Engineering and Natural Sciences, vol. 5, no. 3, pp. 314-321, 2017.

[24] O. Y. Bozkurt, I. C. Dai, O. Ozbek, "The Finite Element Analysis and Geometry Improvements of Some Structural Parts of a Diesel Forklift Truck", Periodicals of Engineering and Natural Sciences, vol. 5, no. 2, pp. 202-209, 2017.

[25] D.C. Montgomery, Design and Analysis of Experiments: 7th ed., New York: Wiley, 2008.

[26] A.I. Khuri and J.A. Cornell, Response Surfaces: Designs and Analyses: New York: Marcel Dekker, 1 996.

[27] C. Yuan, B.G. Liu and C.G. Chen, "Optimization of preparation process of hydroxypropyl- $\beta$ cyclodextrin by response surface methodology," in Proceedings of International Conference on Challenges in Environmental Science and Computer Engineering, Wuhan, China, pp.26-28, Mar. 2010.

[28] S.I. Kim, J.P. Hong, Y.K. Kim, H. Nam and H.I. Cho, "Optimal design of slotless-type PMLSM considering multiple responses by response surface methodology," IEEE Trans. Magn., vol.42, no.4, pp.1 21 9-1 222, Apr. 2006. 
[29] D.K. Hong, B.C. Woo and D.H. Kang, "Application of fractional factorial design for improving performance of $60 \mathrm{~W}$ transverse flux linear motor", J. Appl. Phys., vol.1 03, no.7, pp. 07F1 20:1 -07F1 20:3, Mar. 2008.

[30] B. Duraković, H. Bašić, "Continuous Quality Improvement in Textile Processing by Statistical Process Control Tools: A Case Study of Medium-Sized Company", Periodicals of Engineering and Natural Sciences, vol. 1, no. 1, pp. 36-46, 2013.

[31] B. Duraković, "Design of Experiments Application, Concepts, Examples: State of the Art", Periodicals of Engineering and Natural Sciences, vol. 5, no. 3, pp. 421-439, 2017.s 